
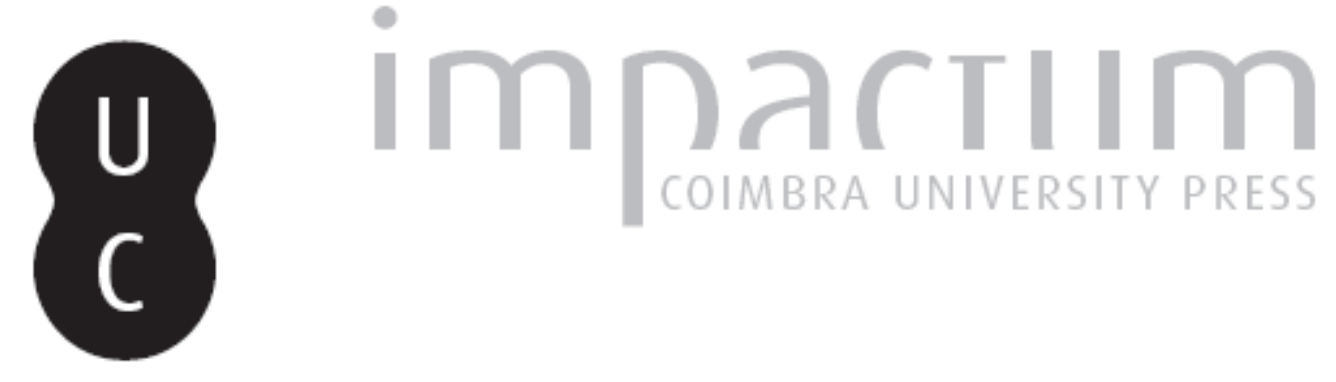

\title{
Roma Vive!: a civilização romana vista pelo cinema
}
Autor(es): $\quad$ Santos, Nídia Catorze
Publicado por: Associação Portuguesa de Estudos Clássicos; Instituto de Estudos Clássicos

URL persistente:

URI:http://hdl.handle.net/10316.2/30455

DOI:

DOI:http://dx.doi.org/10.14195/0872-2110_51_19

Accessed : $\quad$ 26-Apr-2023 14:29:11

A navegação consulta e descarregamento dos títulos inseridos nas Bibliotecas Digitais UC Digitalis, UC Pombalina e UC Impactum, pressupõem a aceitação plena e sem reservas dos Termos e Condições de Uso destas Bibliotecas Digitais, disponíveis em https://digitalis.uc.pt/pt-pt/termos.

Conforme exposto nos referidos Termos e Condições de Uso, o descarregamento de títulos de acesso restrito requer uma licença válida de autorização devendo o utilizador aceder ao(s) documento(s) a partir de um endereço de IP da instituição detentora da supramencionada licença.

Ao utilizador é apenas permitido o descarregamento para uso pessoal, pelo que o emprego do(s) título(s) descarregado(s) para outro fim, designadamente comercial, carece de autorização do respetivo autor ou editor da obra.

Na medida em que todas as obras da UC Digitalis se encontram protegidas pelo Código do Direito de Autor e Direitos Conexos e demais legislação aplicável, toda a cópia, parcial ou total, deste documento, nos casos em que é legalmente admitida, deverá conter ou fazer-se acompanhar por este aviso. 


\section{Boletim de}

\section{Estudos Clássicos}

Associação Portuguesa de Estudos Clássicos Instituto de Estudos Clássicos

Coimbra

Junho de 2009 


\section{ROMA VIVE! \\ A Civilização Romana Vista pelo Cinema}

Está patente ao público, desde 19 de Fevereiro, no Museu de Calatayud, a exposição ROMA VIVE! La Civilización Romana vista desde el Cine. Uma combinação de fotografia e filme, complementada com projecções diárias de $\mathrm{NO}-\mathrm{DO}^{1}$, convida o visitante a pensar a forma como a sétima arte interpretou, retratou e recriou, ao longo do século $\mathrm{XX}$, os episódios mais conhecidos da História Romana, confrontando-o com uma visão sobre duas áreas que se tornaram indissociáveis: a «História de Roma» e o «Cinema da História».

Longe de ser uma civilização desaparecida, Roma continua viva na memória da cultura ocidental, em grande medida graças aos pepla, que foram ao longo dos anos o primeiro e, frequentemente, o único contacto das massas com a Roma dos Césares, apesar do difícil equilíbrio entre a realidade histórica e a liberdade artística. A corrida de carros do Ben-Hur (1959), a entrada de Cleópatra em Roma no filme homónimo, o incêndio da cidade às ordens de Nero, a pega do touro ou a perseguição ao cristianismo emergente no Quo Vadis (1951), continuam a dominar o imaginário de gerações. Foi, aliás, a necessidade de cenários elaborados e monumentais para as filmagens destas produções que esteve na génese dos grandes estúdios cinematográficos.

As fotografias seleccionadas para esta exibição, muitas das quais inéditas e de prestigiados fotógrafos internacionais, provenientes de filmotecas italianas, alemãs e espanholas, revelam os bastidores, a preparação dos cenários, o making of de muitos filmes e os seus protagonistas, como Charlton Heston, Sofia Loren ou Elizabeth Taylor. Algumas mostram Akira

1 O NO(ticiário) DO(cumental) é o diminutivo por que ficaram conhecidas as filmagens oficiais que o estado espanhol fazia durante a ditadura de Franco. Com a duração de um minuto, documentam as filmagens de vários pepla, como A Queda do Império Romano (1964) e Espártaco (1960), que decorreram no país vizinho. A ambos os filmes foi, como não poderia deixar de ser, dado um destaque especial nesta mostra. 
Kurosawa, o cineasta nipónico, enquanto visita os estúdios da Cinecittá, em Roma, durante as filmagens de Ben-Hur ou Sofia Loren numa animada conversa com Sofia da Grécia, futura rainha de Espanha, aquando de uma visita desta última ao cenário do filme A Queda do Império Romano (1964). Um pequeno texto explicativo acompanha todas as fotografias, informando que actores e directores aparecem retratados, assim como curiosidades que marcaram as rodagens. Um exemplo é o Cleópatra (1963), de Joseph L Mankiewicz, que se tornou a filmagem mais famosa e caótica da história do cinema e que arruinou a Fox, mas que despertou um enorme interesse no público, visto que marcou o início do namoro de Elizabeth Taylor e Richard Burton, permitindo ao visitante um melhor enquadramento no momento histórico ou monumento recriado.

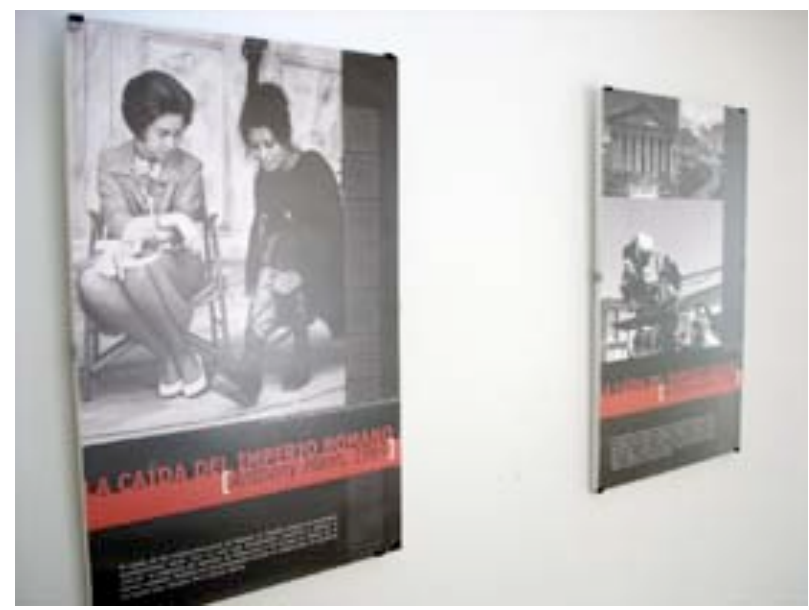

As películas seleccionadas para acompanhar a exibição também se destacam por serem quase desconhecidas do grande público, visto terem menor qualidade ou sido ofuscadas por obras como Ben-Hur, Cleópatra, Quo Vadis, ou mais recentemente, Gladiador (2000) de Ridley Scott. Diariamente os visitantes podem assistir à projecção de Galathea (1935) e La Bella Helena (1917), duas curtas-metragens de animação, realizadas por Lotte Reiniger, uma cineasta alemã, pioneira na sua arte e que se inspirou na mitologia grega para alguns dos seus filmes. 
Galathea, cuja animação é feita à base de sombras chinesas, apresenta um curioso remake do mito de Pigmalião (Ov., Met. 10, 243-297). Este apaixona-se pela estátua de uma bela jovem, por ele esculpida e que se assemelha à própria Afrodite. Quando, de súbito, a estátua ganha vida, toda a cidade fica em sobressalto. Galateia, que apenas pretende divertir-se, recusa as atenções do escultor enamorado. Indiferente às belas roupas e jóias que ele lhe oferece e insensível à sua ameaça de suicídio com um punhal, entrega-se à dança e à bebida na companhia dos homens que a tentam seduzir, para alarme das respectivas esposas. A ordem é finalmente reposta por Afrodite, que se comove com as súplicas que a esposa de Pigmalião lhe dirige. Esta, que sempre esteve em segundo plano no coração do esposo, mostra que o seu amor é de tal forma forte que o auxilia nas vãs tentativas de sedução. Só quando Galateia regressa à sua forma original é que ele se apercebe que a verdadeira beleza é a da sua devotada esposa.

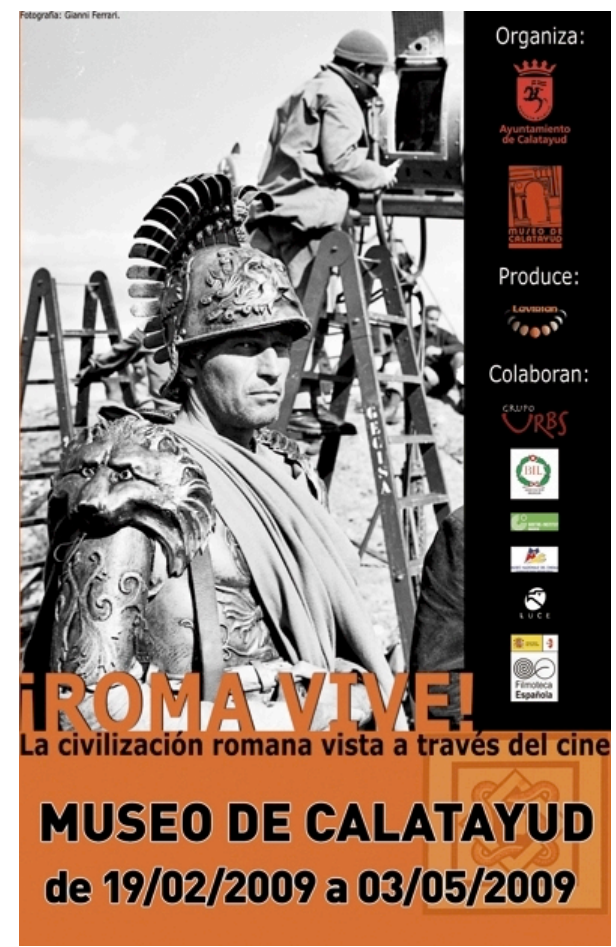


A 11 de Abril de 2009 foi projectado o célebre Cabiria (1914), realizado por Piero Fosco, um pseudónimo de Giovanni Pastrone. Este foi um dos primeiros épicos a serem filmados ainda durante o tempo do cinema mudo e teve um estrondoso sucesso junto do público. $\mathrm{O}$ argumento, escrito propositadamente para o filme, baseia-se no relato de Tito Lívio (29, 23-30), que se centra em dois acontecimentos que marcaram a Segunda Guerra Púnica (218-201 a.C.): o ataque de Cipião a Citra e a famosa expedição naval contra Siracusa, em que Arquimedes desempenhou um papel fundamental na defesa da cidade, ao utilizar um enorme espelho que incendiou a frota romana. No filme, conta-se a história de uma jovem siciliana, Cabiria, levada para Cartago como escrava, onde é salva em duas ocasiões por um espião romano, Fúlvio Axila e pelo musculado escravo deste, Maciste. Os romanos acabam por vencer a guerra e despedimo-nos de Cabiria e Axila que navegam rodeados por anjos. É perceptível a influência decisiva de dois romances históricos que fizeram história: Quo Vadis, na criação de Maciste, claramente inspirado em Urso, escravo de Lígia; e Os Últimos Dias de Pompeia, o modelo para a erupção do Etna e para a aparição do templo pagão.

Filmado em vários locais, de Roma e da Sicília ao Norte de África, foram utilizadas quatro câmaras, uma delas, móvel. Cabiria apresenta já a iconografia que se tornou clássica e que nas décadas seguintes vai caracterizar o Peplum, enquanto género cinematográfico, ao apresentar cenários colossais e milhares de figurantes, para recriar momentos espectaculares, como a travessia dos Alpes pelo exército de Aníbal, o assédio de Siracusa e os espelhos de Arquimedes, a erupção do Etna, o sacrifício humano no templo cartaginês (sendo este uma curiosa síntese da arquitectura egípcia, babilónica e pré-colombiana), ou o suicídio da rainha Sofonisba, que tinha aparecido em cena a acariciar os seus dois leopardos de estimação.

No dia 19 de Abril de 2009 foi projectada a película Rómulo e Remo (conhecido também como Duel of Titans) (1961), realizado por Sérgio Leone e protagonizado por Steve Reeves (Rómulo) e Gordon Scott (Remo). Esta obra foi aclamada pela fidelidade aos textos de Tito Lívio $(1,4,2-16.4)$ e de Plutarco (Vida de Rómulo), na recriação das origens lendárias de Roma. Apesar de deixar de fora personagens como Amúlio, rei de Alba, e Tito Tácio, rei dos Sabinos, passa em revista os momentos fundamentais da fundação da cidade, incluindo o augúrio dos abutres recebido por Rómulo. Abandonados à nascença, dois gémeos são adoptados por uma loba que os amamenta. Quando descobrem que são filhos de Marte, o deus da guerra, Remo sucumbe ao desejo de poder, enquanto o seu irmão apenas deseja viver 
em paz na cidade recém-fundada. O clímax do filme ocorre quando Rómulo, que realiza a investidura cerimonial do rei, demarca com o arado os primeiros sulcos da urbe com dois bois brancos e é interrompido por Remo. Na luta que se segue, Rómulo mata Remo e assume o trono de Roma.

Organizada pela produtora Lavirian e comissariada por Asier Mensuro e Manuel Martín-Bueno, a exposição pôde ser visitada até ao dia 3 de Maio do corrente ano e destacou-se pelo seu carácter itinerante. Durante os meses de Junho a Setembro de 2008 esteve patente ao público no Museu Oiasso, em Irún, onde foi complementada com uma conferência subordinada ao tema $E l$ Cine de Romanos: Entre la Imaginación y la Realidad Histórica, proferida por Asier Mensuro e por um conjunto de iniciativas dedicadas aos mais jovens e ao público sénior. Amphitryon, uma produção musical germânica, realizada por Reinhold Schünzel em 1935, onde se recupera a lenda do nascimento de Hércules, tal como foi transmitida por Plauto no seu Anfitrião, foi a película escolhida para aí acompanhar a exibição, a par das curtasmetragens Galathea (1935) e La Bella Helena (1917). Amphitryon, que tinha como subtítulo Aus den Wolken Kommt das Glück (A sorte chega das nuvens), apresenta-se como uma mistura de opereta com um musical da Broadway, com um diálogo lírico e algumas canções pelo meio. O enredo é tipicamente plautino, dominado pelas confusões criadas pelas identidades trocadas e pelas intricadas relações amorosas. Júpiter e Mercúrio bebem uma poção para se transformarem, respectivamente, no belo Anfitrião e no seu escravo Sósia. Graças a esta artimanha, Júpiter seduz e engravida a esposa de Anfitrião. A chegada inesperada dos verdadeiros Anfitrião e Sósia precipitam a acção que é adensada pela constipação que o agora mortal Pai dos Deuses apanha e pela sua embriaguez. A farsa só termina quando Juno desce do Olimpo com um enorme cisne mecânico e o leva para a morada dos deuses, devolvendo-lhe a sua aparência e dignidade.

Esta exposição concretiza e confirma também uma nova tendência, que se vem impondo nos Estudos Clássicos, em que os estudos pioneiros de Maria Wyke e Martin Winkler, entre outros, mostraram que os filmes épicos foram fortemente influenciados pelas fontes do século XIX, desde romances históricos como o Sinal da Cruz de Wilson Barrett (1895) ou o Quo Vadis de Henryk Sienkiewicz (1896) a peças de teatro, passando pela pintura, ópera ou exposições museológicas. A sua interpretação destes discursos históricos procurava garantir a autenticidade histórica, de forma a seduzir as audiências cada vez mais atraídas pelo passado. 
O Museu de Catalayud, reaberto em 2007, depois de sofrer obras de ampliação das suas instalações, e que acolhe, entre as suas exposições permanentes, o espólio arqueológico recolhido nas escavações da cidade romana de Bilbilis (de onde era natural o poeta Marcial e onde se destacam os frescos, encontrados em várias habitações e nas termas, moedas, jóias e inscrições), oferece, assim, aos seus visitantes, uma experiência museológica ímpar. Assiste-se a uma exposição de cinema dentro do cinema, que em simultâneo narra a história de muitos dos objectos arqueológicos expostos ${ }^{2}$.

NÍDIA CATORZE SANTOS

\section{AS BACANTES DE EURÍPIDES PELA COMPANHIA DE TEATRO DE BRAGA}

A 13 de Janeiro do corrente ano, no Theatro Circo, em Braga, estreou o exercício teatral sobre As Bacantes de Eurípides que, para a Companhia de Teatro de Braga (CTB), dirigiu o encenador Rui Madeira. A peça, em cena nesse espaço até 23 de Janeiro, iniciou em seguida uma digressão que a fez passar por Coimbra - onde esteve, no Teatro da Cerca de S. Bernardo, nos passados dias 7 e 8 de Março - e que a levou mesmo a terras brasileiras, a 21 de Abril. Anunciada, na folha de sala, como "um espectáculo em progressão" e como resultado do "entendimento que [o grupo vem fazendo] sobre a leitura dos clássicos e da relação dessa leitura com o trabalho dos actores, numa perspectiva do seu próprio crescimento artístico", a peça enforma de faltas que consideramos graves e que não se coadunam, estamos em crer, com a liberdade (quase ilimitada) de um encenador de teatro que escolhe trabalhar um texto clássico.

Embora susceptíveis de constranger um espectador mais canónico e tradicional de teatro clássico, são ainda assim legítimas e coerentes algumas opções cénicas, que se resumem numa intenção de adaptação do drama euripidiano a um espectáculo chocante, que roça o fetichista. Refiro-me, entre outros aspectos, à transformação do palácio de Penteu num aglomerado de grades de cerveja Sagres - patrocinador mais do que assumido do

${ }^{2}$ Gostaríamos de expressar o nosso agradecimento à produtora Lavirian por todos os esclarecimentos prestados. 